\title{
A Phonocardiographic Study of Patients with Multiple Starr-Edwards Prosthetic Valves ${ }^{\star}$
}

\author{
O. WILLIS BOICOURT, J. DAVID BRISTOW, ALBERT STARR, AND \\ HERBERT E. GRISWOLD
}

\begin{abstract}
From the Division of Cardiology of the Department of Medicine and the Division of Cardiopulmonary Surgery,
\end{abstract} Department of Surgery, University of Oregon Medical School, Portland, Oregon, U.S.A.

In recent years physicians have been presented with new auscultatory syndromes due to the increasing use of prosthetic heart valves. It is the purpose of this paper to describe phonocardiograms of patients who have multiple ball valve prostheses of the type described by Starr and Edwards (1961) and Starr et al. (1963). The sharp sounds produced by the opening and closing of these valves allow timing of several physiological events in the cardiac cycle. In addition, analysis of these recordings in patients with atrial fibrillation shows the deleterious effect of fast heart rate on prosthetic valve function.

\section{SUBJECTS AND METHODS}

Studies were done on 16 patients from two weeks to two years after multiple valve replacement with StarrEdwards prosthetic valves. Their ages ranged from 23 to 51 years. Of these 16,10 had prosthetic mitral and aortic valves, one had mitral and tricuspid prostheses, and 5 had replacement of aortic, mitral, and tricuspid valves. There were 9 patients with sinus rhythm, 4 with atrial fibrillation, and one with atrial flutter. In the remaining 2 patients, records were made during atrial fibrillation and after electrical conversion to sinus rhythm.

Phonocardiograms were recorded with a Sanborn Model 500 photographic recorder. Diaphragm microphones were simultaneously placed at the apex and at the left sternal border in the 2nd intercostal space or in the 4th and 5th intercostal spaces. Occasionally a microphone was placed at the right sternal border as well. The indirect carotid pulse was obtained by a bell pressed over the carotid artery. The paper speed was

Received August 16, 1965.

* Supported by Program Project Grant HE-06336-03 of the U.S. Public Health Service.

$2 \mathrm{M}$
$100 \mathrm{~mm}$. $/ \mathrm{sec}$., allowing analysis of intervals to $0.005 \mathrm{sec}$. At least 15 complexes were analysed in patients with atrial fibrillation, and at least five were studied in patients with sinus rhythm. Isoprenaline was given by intravenous infusion in order to speed the rate in one patient with three prostheses and sinus rhythm. Records were obtained during the administration of the drug and shortly after it was stopped, but before the heart rate had returned to resting level.

\section{RESULTS}

An ejection type systolic murmur (Leatham, 1958) was present at the left sternal border, aortic area, or apex of all patients with prosthetic aortic valves. A murmur was not found in the single patient with mitral and tricuspid prostheses. The murmurs varied from soft to moderately loud (grade 3/6), and in some patients were not recorded since the controls were set for optimum recording of the valve sounds. The murmurs began with aortic opening and lasted through the first two-thirds of the ejection phase (Fig. 1).

The valve opening and closing sounds were discrete, high-pitched clicks. The tricuspid valve sounds at the left sternal border were louder than the mitral sounds, an observation perhaps explained by the more anterior position of the tricuspid valve in the chest. After very long $R-R$ intervals in patients with atrial fibrillation, the mitral and tricuspid closure sounds were very soft, suggesting that the balls had returned nearly to the closed positions before the onset of systole (Fig. 1).

Mitral and Aortic Prostheses. In the 10 patients with mitral and aortic prostheses, 4 sounds were easily identified in each cardiac cycle (Fig. 1). 


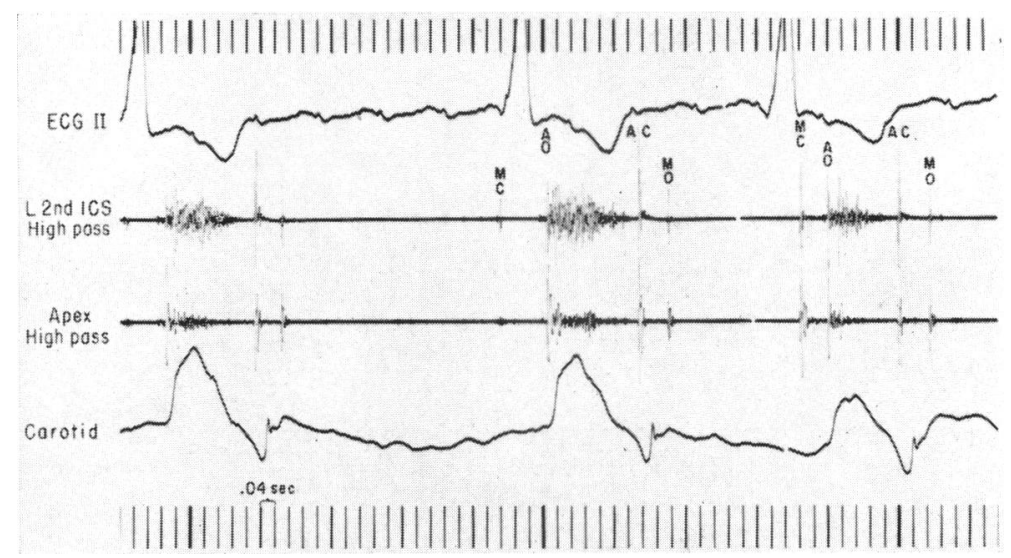

Fig. 1.-Record from Patient 2 with aortic and mitral prostheses and atrial flutter. The systolic ejection murmur is loud. In the second cycle, after a long diastolic pause, the mitral closure sound is soft and simultaneous with the $Q$ wave. The next diastole is shorter and the mitral closing sound is louder and later than in the preceding cycle. In this and the following illustrations the valve sounds are designated thus: $M C=$ mitral closing; $\mathrm{MO}=$ mitral opening; $\mathrm{AC}=$ aortic closing; $\mathrm{AO}=$ aortic opening; $\mathrm{TC}=$ tricuspid closing $; \mathrm{TO}=$ tricuspid opening.

With the onset of systole there was a mitral closing sound closely followed by an aortic opening sound. Aortic closure occurred at the end of ejection, and finally there was the opening click of the mitral valve in early diastole. The interval from mitral closure to aortic opening corresponds with isometric contraction, though it is recognized that a finite time is necessary for ball travel in both valves. Similarly, time from aortic closure to mitral opening is a measure of isometric relaxation.

Mitral, Tricuspid, and Aortic Prostheses. In addition to the characteristic findings with mitral and aortic prostheses, these patients had tricuspid valve sounds soon after the mitral opening and closing sounds. Thus systole was announced by mitral closure, tricuspid closure, and aortic opening. At the end of ejection aortic closure occurred, followed in early diastole by the opening of the mitral and tricuspid valves which produced a split "opening snap." Sometimes, however, the tricuspid valve sound would be superimposed on either the mitral closure sound or aortic opening click in early systole, and only two sounds were recorded at this time. In diastole the opening clicks of the tricuspid and mitral valves were sometimes superimposed so that only one "opening snap" was recorded (Fig. 2). Splitting of the A-V valvular opening clicks with inspiration was demonstrated in the patient with mitral and tricuspid prostheses. There was no respiratory effect on the interval from the $Q$ wave to the sounds of tricuspid and mitral valve closure, however (Fig. 3).
Additional sounds with phonocardiographic characteristics of valve sounds were noted in 4 patients: 2 had clicks at the time of a 4 th heart sound, and 2 had clicks at the time of the 3rd heart sound. One of the latter also displayed several tiny clicks in early diastole after mitral valve opening.

Intervals. The discrete valve opening and closing sounds allowed accurate measurement of the timing of various events in the cardiac cycle. Table I lists these results in our patients and some normal values from earlier publications (Braunwald et al., 1955; Braunwald, Fishman, and Cournand, 1956). The duration of total systole, isometric contraction, and ejection vary inversely with rate (Wallace et al., 1963). The heart rate at which the normal values were measured was not stated; however, the normal subjects were patients under anaesthesia who had thoracic operations, and rate presumably was not unusually fast or slow.

In our patients mitral closure occurred at a time later after the $Q$ wave of the cardiogram than the time observed by Braunwald in normal subjects. Isometric contraction, measured from mitral closure to aortic opening, was within Braunwald's normal range in all the patients except one with three prosthetic valves and right bundle-branch block.

In patients with atrial fibrillation, varying $R-R$ intervals allow differing lengths of time for filling of the ventricles in diastole. Therefore, in mitral stenosis, end-diastolic left atrial pressure varies with ventricular filling time, being lower after a 


\section{||||||||||||||||||||||||||||||||||||||||}

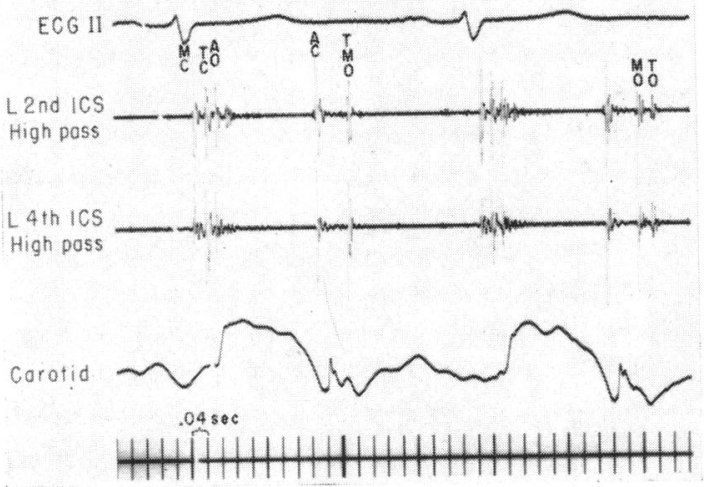

A

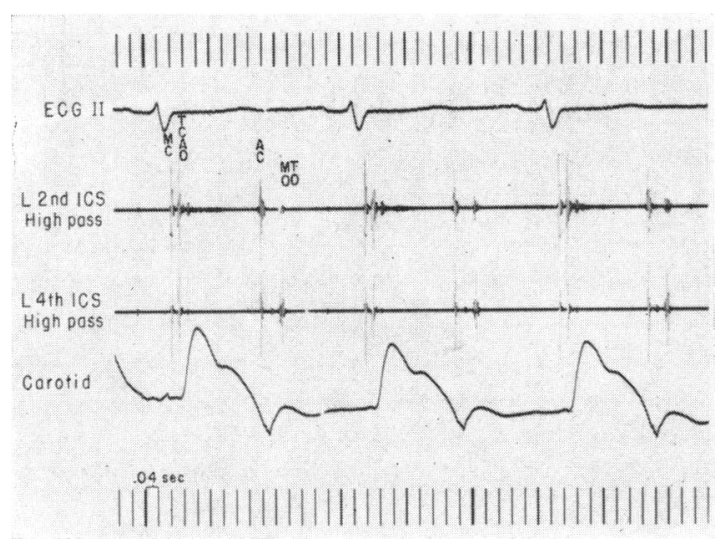

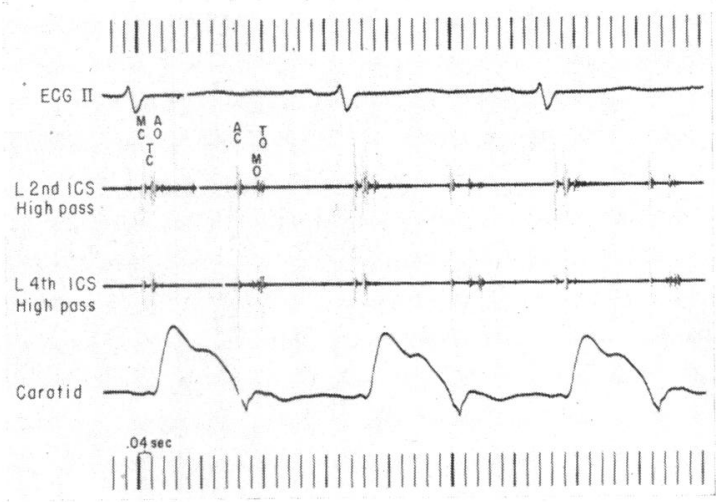

C

FIG. 2.-Phonocardiogram of Patient 15 with mitral, aortic, and tricuspid prostheses.

(A) At rest. There are three distinct valve sounds soon after the $Q$ wave of the cardiogram. A soft systolic murmur is present. In the first complex the mitral and tricuspid opening sounds are fused, but they are split in the second one. A soft atrial sound is present between the $\mathbf{P}$ wave and QRS.

(B) During isoprenaline infusion. Isometric contraction is rapid and the aortic opening sound is superimposed on tricuspid closure. The mitral and tricuspid opening sounds are nearly simultaneous.

(C) During recovery from isoprenaline infusion. Tricuspid closing and aortic opening sounds are distinct, but not as widely separated as in $2(\mathrm{~A})$.

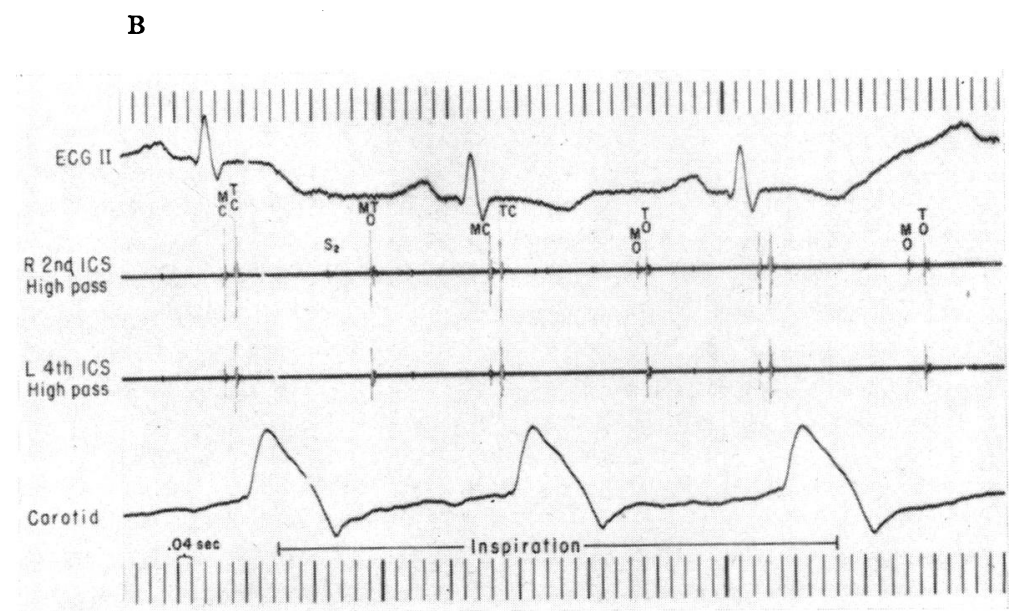

Fig. 3.-Tracing from Patient 16 with mitral and tricuspid prosthetic valves. No murmur is present. Note the splitting of the opening prosthetic valve sounds with inspiration. They are superimposed in the first complex which occurred at the very end of expiration. 
TABLE I

CLINICAL, CARDIOGRAPHIC, AND PHONOCARDIOGRAPHIC DATA IN 16 PATIENTS WITH STARR-EDWARDS PROSTHETIC VALVES

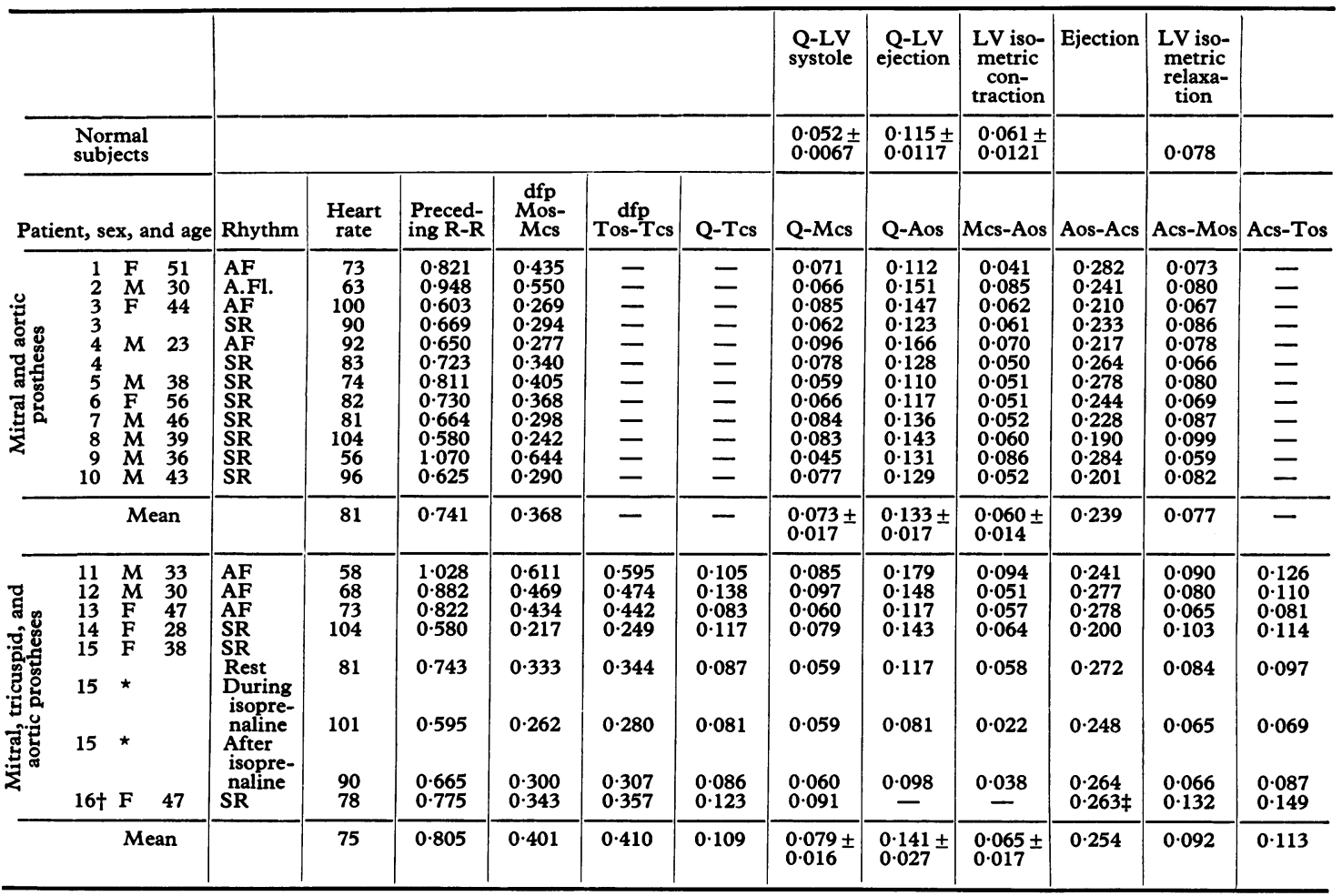

The values listed are means for all the observations on each individual patient. All intervals are in seconds. dfp $=$ diastolic filling period; $Q=Q$ wave of cardiograph; Tos=Tricuspid opening sound; Tcs=Tricuspid closing sound; Mos=Mitral opening sound; $M c s=$ Mitral closing sound; Aos = Aortic opening sound; Acs = Aortic closing sound.

* Not used in calculation of group means.

$\dagger$ Mitral and tricuspid prostheses.

$¥$ Carotid ejection time.

long diastolic pause which gives more time for the atrium to become decompressed. When left atrial pressure is low, the Q-1st heart sound interval is short, since rising ventricular pressure quickly exceeds low atrial pressure. In our patients with atrial fibrillation, the interval from $Q$ wave to mitral closure varied inversely with the preceding R-R interval (Fig. 4), suggesting that atrial pressure was lower after a long diastolic pause than after a short one. With heart rates of 60 or below, mitral closure occurred immediately after the $Q$ wave, and the sound was of very small amplitude (Fig. 1).

With low atrial pressure the interval between the second sound and mitral valve opening click is long, since more time is required for ventricular pressure to fall below atrial and allow the A-V valves to open. Though there was a tendency in our patients with atrial fibrillation for the interval between aortic closure and mitral opening to vary directly with the preceding $R-R$ interval, this was not consistent.

As a measure of the time available for ventricular filling, we used the period between the opening and closing clicks of the prosthetic mitral and tricuspid valves. The actual diastolic filling period is perhaps slightly longer than the interval between the valve sounds, since the ball must take a short time to travel in the cage before making a sound, both at opening and at closure. Despite these limitations, certain correlations could be made. In those patients with atrial fibrillation, the diastolic filling period varied inversely with the heart rate, as expected, since systolic time per minute increases with heart rate, while diastolic 


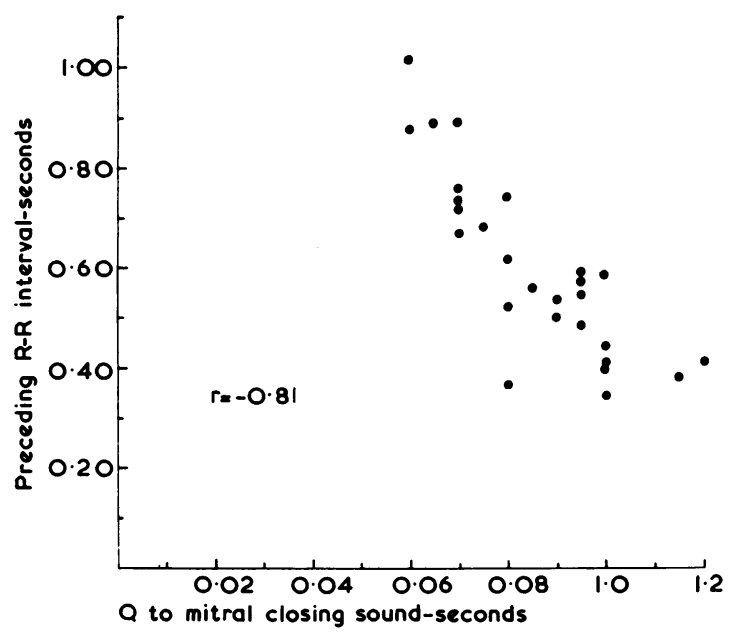

Fig. 4.-Relation between the preceding $R-R$ interval and the $Q$ to closing valve sound interval in Patient 3 with aortic and mitral prostheses and atrial fibrillation. There is some variation for any particular rate, but an inverse relation is shown.

time decreases (Levine et al., 1962). In 2 patients with some very short $R-R$ intervals, measurements at fast heart rates were obtained. The phonocardiogram of one of these patients is shown in Fig. 5, and the graph of heart rate and diastolic filling period is shown in Fig. 6A. It is clear that as the heart rate approaches 180 , the diastolic filling period becomes very short. Indeed, when the distribution curve is extrapolated the short distance to the $\mathrm{Y}$ axis, it is suggested that diastolic filling would cease at a heart rate of 189 . The validity of this observation is supported by the several measured points which occurred very close to this value and by the very similar slopes of the lines in all the other patients with atrial fibrillation. The calculated regression equation for each patient allowed prediction of the heart rate at which diastolic filling would cease. These values are shown in Table II for the patients with atrial fibrillation or flutter.

Isoprenaline Effect. In order to speed the heart rate, isoprenaline was given by intravenous infusion to one patient with three prostheses and sinus rhythm. The interval between the $Q$ wave and the tricuspid valve closure sound shortened, isometric contraction was more rapid, and ejection was shorter. During the height of the drug effect, the tricuspid closure and aortic opening sounds were superimposed (Fig. 3). The mitral and tricuspid opening sounds moved nearer the aortic closure sound during drug administration.

Effect of the Number of Prostheses and Rhythm. No statistically significant differences were found in the measured intervals of patients with three

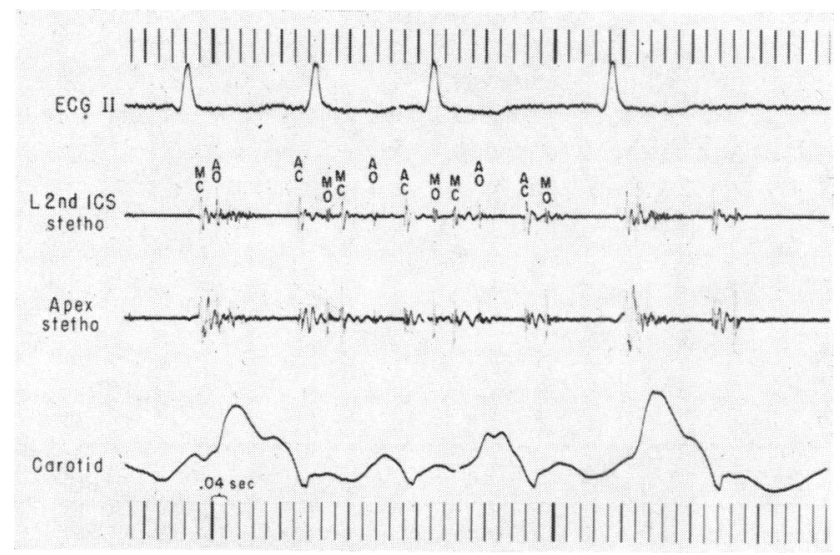

FIG. 5.-Phonocardiogram of Patient 3 with aortic and mitral prostheses and atrial fibrillation with a fast ventricular rate. A profusion of valve sounds is present, but the valves open and close in the usual order. The $R-R$ interval between the first and second complexes is 0.380 sec. (heart rate 158) and between the second and third is $0.345 \mathrm{sec}$. (heart rate 174). Diastolic filling period (dfp) is very brief in both. Between the first and second complexes dfp is 0.045 sec.; however, between the second and third, $\mathrm{dfp}$ is 0.060 sec. despite the shorter $\mathbf{R}-\mathbf{R}$ interval. This increase in filling occurs largely because ejection (AO-AC) is much shorter between the second and third complexes than between the first and second. The interval from aortic closure to mitral opening is shown to be only slightly shortened at these fast rates when compared with the fourth complex with a much longer $R-R$ interval $(0.520$ sec.; heart rate 115$)$. 


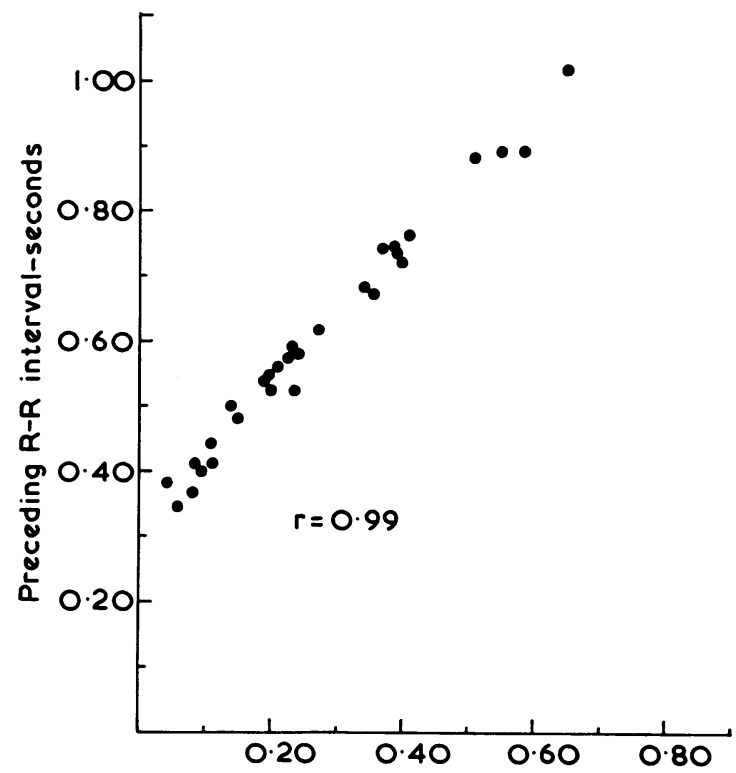

Mitral diastolic filling period-seconds

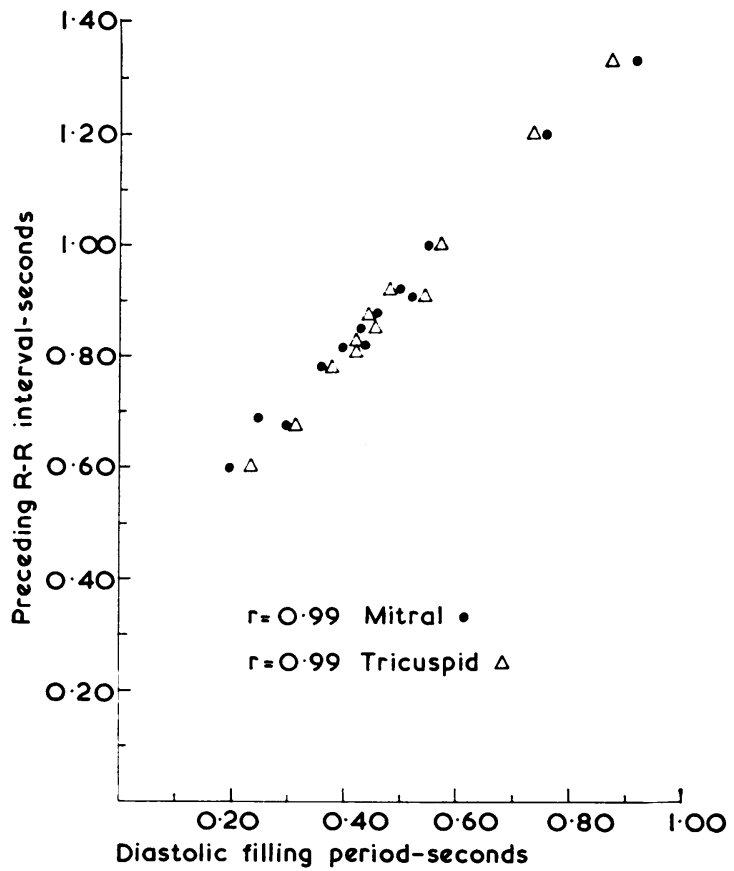

B

FIG. 6.-(A) Relation between R-R interval and mitral diastolic filling period in Patient 3 whose phonocardiogram is shown in Fig. 5. Several measurements were obtained at short $R-R$ intervals where diastolic filling time is very brief.

(B) A graph of $R-R$ interval and diastolic filling period in Patient 12 with three prosthetic valves. The slopes of the calculated regression lines of the mitral and tricuspid distributions are practically identical, and very similar to the slope of the line in $\mathrm{A}$, though when extrapolated the $\mathrm{Y}$ intercepts would be slightly different.

prostheses as opposed to those with two, or in patients with sinus rhythm when compared with those with atrial fibrillation or flutter. However, significant individual differences were found. Both the patients in whom measurements were made before and after conversion to sinus rhythm had shortening of the interval from $Q$ wave to mitral closure after conversion (Table I). Although their slower heart rates with sinus rhythm would produce a shortening of this interval, the amount of shortening observed appeared to be more than could be accounted for by rate change alone. Hultgren and Hubis (1965) have made similar observations. This suggests that atrial systole facilitates closure of prosthetic mitral valves, a phenomenon observed with normal valves as well (Sarnoff, Gilmore, and Mitchell, 1963).

\section{Discussion}

Previous reports on phonocardiography after

TABLE II

CALCULATED REGRESSION EQUATIONS FOR 7 PATIENTS WITH STARR-EDWARDS PROSTHESES IN ATRIAL FIBRILLATION

\begin{tabular}{|c|c|c|c|c|c|c|c|}
\hline Patient & Valve & $\begin{array}{c}\text { Correlation } \\
\text { coefficient }\end{array}$ & $\begin{array}{c}\text { Slope of } \\
\text { distribution }\end{array}$ & $\begin{array}{c}\text { Longest R-R } \\
\text { observed (sec.) }\end{array}$ & $\begin{array}{c}\text { Shortest R-R } \\
\text { observed (sec.) }\end{array}$ & $\begin{array}{c}\mathbf{R}-\mathbf{R} \text { interval } \\
\mathbf{Y} \text { intercept }\end{array}$ & $\begin{array}{c}\text { Heart rate at } Y \\
\text { intercept }\end{array}$ \\
\hline $\begin{array}{r}1 \\
2 \\
3 \\
4 \\
11 \\
11 \\
12 \\
12 \\
13 \\
13\end{array}$ & $\begin{array}{l}\text { Mitral } \\
\text { Mitral } \\
\text { Mitral } \\
\text { Mitral } \\
\text { Mitral } \\
\text { Tricuspid } \\
\text { Mitral } \\
\text { Tricuspid } \\
\text { Mitral } \\
\text { Tricuspid }\end{array}$ & $\begin{array}{l}0.99 \\
0.97 \\
0.99 \\
0.99 \\
0.99 \\
0.99 \\
0.99 \\
0.99 \\
0.96 \\
0.96\end{array}$ & $\begin{array}{l}1.061 \\
1.095 \\
1.061 \\
1.060 \\
1.077 \\
1.023 \\
1.025 \\
1.149 \\
1.105 \\
1.048\end{array}$ & $\begin{array}{l}1.180 \\
1.265 \\
1.015 \\
1.060 \\
1.730 \\
1.730 \\
1.330 \\
1.330 \\
0.975 \\
0.975\end{array}$ & $\begin{array}{l}0.580 \\
0 \cdot 685 \\
0 \cdot 345 \\
0 \cdot 380 \\
0.740 \\
0 \cdot 740 \\
0 \cdot 600 \\
0 \cdot 600 \\
0 \cdot 630 \\
0.630\end{array}$ & $\begin{array}{l}0.359 \\
0.342 \\
0.317 \\
0.341 \\
0.384 \\
0.401 \\
0.401 \\
0.337 \\
0.343 \\
0.358\end{array}$ & $\begin{array}{l}167 \\
175 \\
189 \\
176 \\
160 \\
150 \\
150 \\
178 \\
175 \\
168\end{array}$ \\
\hline
\end{tabular}


valve replacement have discussed the characteristic sounds produced by the prosthesis and have reported the presence of additional sounds at the time of the usual 3rd and 4th heart sounds. In addition, multiple high-pitched sounds have been noted in diastole (Hultgren and Hubis, 1965; Zitnik and Burchell, 1963; Strach, Judson, and Ardaiz, 1963).

The murmur noted in our patients with aortic prosthesis is probably due to turbulent blood flow through the aortic valve. Cardiac catheterization studies (Bristow et al., 1964) have shown small pressure gradients across the Starr-Edwards prosthetic aortic valve. Since the mitral prosthesis projects into the aortic outflow tract, it too can produce turbulence, and many patients with only a mitral prosthesis have a systolic ejection murmur.

Cardiac catheterization studies have shown small pressure gradients across Starr-Edwards mitral prostheses (Morrow et al., 1964; Judson et al., 1964; Bristow et al., 1965), and the phonocardiographic findings might be expected to be similar to those in patients with mild mitral stenosis. Zitnik and Burchell (1963) have pointed out that the mitral prosthetic sounds in patients with atrial fibrillation vary with the $R-R$ interval as they do in patients with a mildly stenotic mitral valve. They observed no effect of respiration on the interval from aortic closure to mitral opening. We did not find a good direct relationship between the R-R interval and the aortic closure to mitral opening interval. There was an inverse relationship between the $R-R$ interval and the interval from the $Q$ wave to mitral or tricuspid closure, however. The mitral and tricuspid opening sounds split with inspiration and closed with expiration as did the normal second heart sounds.

The effect of heart rate on diastolic filling period is interesting. Diastolic filling may not actually be abolished by heart rates near 180, since atrial and systemic venous pressures may rise enough to cause the valves to open sooner than the extrapolated graph suggests. It is obvious, however, that the filling interval is seriously reduced at moderately rapid rates. The reason for the disproportionate reduction in diastolic filling is that at rapid rates isometric contraction, ejection, and isometric relaxation are normally proportionately less shortened than is diastolic filling period. In addition, in these patients with prosthetic valves, the interval from aortic closure to mitral opening is relatively fixed, varying only a few hundredths of a second from slow to very fast heart rates. At fast rates, this interval encroaches considerably on diastolic filling time (Fig. 5). Therapeutic implications are obvious. Atrial fibrillation with rapid ventricular rate and other fast arrhythmias are known to be poorly tolerated by patients with prosthetic mitral valves, and prompt treatment of these arrhythmias is indicated.

Left atrial and left ventricular diastolic pressure relationships are two of the factors causing variation in the timing of the mitral prosthetic valve sounds. The inertia of the ball and the position of the ball in the cage at the onset of systole are two additional factors. A finite amount of time must be necessary for the ball to come into motion and to travel to strike the valve ring or the top of the cage. If it starts from less than the fully open position, it will close sooner than if it has to travel the full length of the cage. Hultgren and Hubis (1965) have reported that the loudness of the mitral closing click varied inversely with the preceding $R-R$ interval. In patients with slow heart rates, the small size of the mitral closing sound and its early appearance after the $Q$ wave of the electrocardiogram suggest that the ball has returned almost to the closed position before the onset of systolic contraction causes it to strike the seat. Variations in the degree of the return of the ball to the closed position could cause the variations in the interval between the $Q$ wave and valve closure sound similar to those we have observed and ascribed to variations in the left atrial pressure. Previous phonocardiographic studies of patients with mitral stenosis have shown that at slow heart rates ( 60 or below) the $Q$ wave/first heart sound and second heart sound/ opening snap relationships are not a reliable guide to the severity of mitral stenosis (Craige, 1957). At slow rates the early closing of the mitral valve in our patients may be due to partial return of the ball to the closed position before the onset of systole, while at faster rates the left atrial pressure may be the determining factor in the movement of the valve closure sounds.

\section{SUMMARY AND CONCLUSIONS}

Phonocardiograms have been recorded in 16 patients after multiple valve replacement with Starr-Edwards prostheses. The closing sounds of the mitral and tricuspid prostheses vary with the heart rate in a manner similar to those of a slightly stenotic mitral valve. Analysis of intervals during the cardiac cycle is facilitated by the discrete valve sounds. At rates of over 150 diastolic filling time is greatly reduced, suggesting that arrhythmias with rapid ventricular rate should be treated promptly in patients with mitral or tricuspid prostheses.

\section{REFERENCES}

Braunwald, E., Fishman, A. P., and Cournand, A. (1956). Time relationship of dynamic events in the cardiac chambers, pulmonary artery and aorta in man. Circulat. Res., 4, 100. 
_, Moscovitz, H. L., Amram, S. S., Lasser, R. P., Sapin, S. O., Himmelstein, A., Ravitch, M. M., and Gordon, A. J. (1955). Timing of electrical and mechanical events of the left side of the human heart. $\mathcal{F}$. appl. Physiol., 8, 309.

Bristow, J. D., Farrehi, C., McCord, C. W., Starr, A., and Griswold, H. E. (1965). Clinical and hemodynamic observations after combined aortic and mitral replacement. In American Heart Association Monograph no. 11: Cardiovascular Surgery, 1964. Circulation, 31, Suppl. no. 1, p. 1-67.

-, McCord, C. W., Starr, A., Ritzmann, L., and Griswold, H. E. (1964). Clinical and hemodynamic results of aortic valvular replacement with a ball-valve prosthesis. In American Heart Association Monograph no. 7: Cardiovascular Surgery, 1963. Circulation, 29, Suppl., p. 36.

Craige, E. (1957). Phonocardiographic studies in mitral stenosis. New Engl. F. Med., 257, 650.

Hultgren, H. N., and Hubis, H. (1965). A phonocardiographic study of patients with the Starr-Edwards mitral valve prosthesis. Amer. Heart f., 69, 306.

Judson, W. E., Ardaiz, J., Strach, T. B. J., and Jennings, R. S. (1964). Postoperative evaluation of prosthetic replacement of aortic and mitral valves. In American Heart Association Monograph no. 7: Cardiovascular Surgery, 1963. Circulation, 29, Suppl, p. 14.

Leatham, A. (1958). Auscultation of the heart. Lancet, 2, $703,757$.
Levine, H. J., Neill, W. A., Wagman, R. J., Krasnow, N., and Gorlin, R. (1962). The effect of exercise on mean left ventricular ejection rate in man. $\mathcal{F}$. clin. Invest., 41, 1050.

Morrow, A. G., Clark, W. D., Harrison, D. C., and Braunwald, E. (1964). Prosthetic replacement of the mitral valve. Operative methods and the results of preoperative and postoperative hemodynamic assessments. In American Heart Association Monograph no. 7: Cardiovascular Surgery, 1963. Circulation, 29, Suppl. p. 2.

Sarnoff, S. J., Gilmore, J. P., and Mitchell, J. H. (1963). Influence of atrial contraction and relaxation on closure of mitral valve. Circulat. Res., 11, 26.

Starr, A., and Edwards, M. L. (1961). Mitral replacement: Clinical experience with a ball-valve prosthesis. Ann. Surg., 154, 726.

,-- McCord, C. W., and Griswold, H. E. (1963). Aortic replacement: Clinical experience with a semirigid ball-valve prosthesis. Circulation, 27, 779.

Strach, T. B. J., Judson, W. E., and Ardaiz, J. (1963). Comparison of phonocardiographic studies before and after replacement of aortic or mitral valves with StarrEdwards prosthesis (Abstract). Circulation, 28, 814.

Wallace, A. G., Mitchell, J. H., Skinner, N. S., and Sarnoff, S. J. (1963). Duration of the phases of left ventricular systole. Circulat. Res., 12, 611.

Zitnik, R. S., and Burchell, H. B. (1963). A phonocardiographic study of patients with total prosthetic mitral valve replacement. Dis. Chest, 44, 11. 